\title{
PACTO NACIONAL PELO FORTALECIMENTO DO ENSINO MÉDIO: A FORMAÇÃO CONTINUADA DE PROFESSORES DE GEOGRAFIA DA REDE ESTADUAL DE ENSINO NO MUNICÍPIO DE AQUIDAUANA - MS
}

\author{
NATIONAL AGREEMENT FOR HIGH SCHOOL STRENGTHENING: \\ THE CONTINUING EDUCATION OF GEOGRAPHY TEACHERS \\ IN THE STATE EDUCATION SYSTEM OF THE MUNICIPALITY \\ OF AQUIDAUANA - MATO GROSSO DO SUL - BRAZIL \\ PACTO NACIONAL POR EL FORTALECIMIENTO DE LA \\ ENSEÑANZA SECUNDARIA: LA FORMACIÓN CONTINUA \\ DEL PROFESORADO DE GEOGRAFÍA DE LA RED ESTATAL DE \\ EDUCACIÓN EN EL MUNICIPIO AQUIDAUANA - MS \\ Raphael de Leão Duarte - Universidade Federal de Mato Grosso do \\ Sul - Aquidauana - Mato Grosso do Sul - Brasil \\ raphaeldeleao@hotmail.com
}

Vicentina Socorro da Anunciação - Universidade Federal de Mato Grosso do Sul - Aquidauana - Mato Grosso do Sul - Brasil vanunciacaoufms@gmail.com

\begin{abstract}
Resumo
Estudos sobre políticas públicas direcionadas ao ensino médio têm provado que existem lacunas em seu processo de planejamento e implementação que necessitam ser superadas. Tal hiato é evidência de uma situação contraditória entre o que se planeja para educação de nível médio e o que é esperado pelo público alvo. Tais problemáticas têm demonstrado a relevância de manter um processo contínuo de acompanhamento dessas políticas públicas. Neste sentido, este artigo traz uma análise da implantação e implementação do Pacto Nacional pelo Fortalecimento do Ensino Médio na Rede Estadual de Ensino no Município de Aquidauana - MS, enfatizando a formação continuada dos professores de geografia. Os procedimentos metodológicos envolveram levantamento de referencial teórico, observações durante as etapas da formação continuada oferecida pelo Pacto na Rede Estadual de Ensino de Aquidauana, pesquisa documental, entrevistas com os professores de geografia e análise de dados. Para somar à discussão, recorreu-se à pesquisa bibliográfica versando sobre o cotidiano docente. 0 estudo aponta contribuições para a formação do professor de geografia e com as políticas públicas educacionais, na perspectiva de encontrar medidas para a promoção da valorização do profissional da educação, desenvolvimento de metodologias de ensino, bem como para o desenvolvimento do ensino médio num contexto mais amplo.

Palavras-chave: Políticas públicas, formação continuada, geografia.
\end{abstract}

\section{Abstract}

Studies on public policies focused on high school have proved that there are gaps in its planning and implementation process that need to be overcome. Such gap indicates a contradictory situation between what 
is planned to high school education and what is expected by the target audience. These issues have shown the importance of keeping a continuous process of monitoring these public policies. Therefore, the present article gives an analysis of the deployment and implementation of the Pacto Nacional pelo Fortalecimento do Ensino Médio (National Agreement for High School Strengthening) in the State Education System on the Municipality of Aquidauana - Mato Grosso do Sul, emphasizing the continuing education of geography teachers. The methodological procedures included a survey of theoretical background, observation during the stages of continuing education offered by the Agreement in the State Education System of Aquidauana, documental research, interviews with geography teachers, and data analysis. Adding to the discussion, literature dealing with daily teaching was researched. This study points out contributions to geography teacher education and educational public policies, aiming to find measures to promote the professionals of education, the development of teaching methodologies, as well as the development of high school in a wider context.

Keywords: Public policies, continuing education, geography.

\section{Resumen}

Estudios sobre políticas públicas direccionadas a la Enseñanza Secundaria han demostrado que existen lagunas en el proceso de planificación y ejecución que deben ser superadas. Este hecho es prueba de una situación contradictoria entre lo que se planea para la educación secundaria y lo que es esperado por el público. Esos problemas han demostrado la importancia de mantener un proceso continuo de monitoreo de esas políticas públicas. Sobre eso, en este trabajo se presenta un análisis relacionado a la implementación y aplicación del Pacto Nacional por el Fortalecimiento de la Enseñanza Secundaria de las escuelas públicas de la ciudad de Aquidauana/MS, enfatizando la formación continua del profesorado de geografía e, igualmente, con las políticas públicas educativas, con el objetivo de encontrar medidas eficaces para la promoción de la valorización del profesional de la educación, desarrollo de metodologías de enseñanza, así como para el desarrollo de la Educación Secundaria en un contexto más amplio.

Palabras clave: Políticas públicas, educación continua, geografía.

\section{Introdução}

No conjunto de temas tratados em estudos e debates sobre a educação brasileira, o ensino médio vem galgando destaque. Por meio da realização e divulgação de pesquisas educacionais com abordagens no campo político, acadêmico e científico, diversidades de questões vêm sendo sistematizadas, que podem ser associadas tanto aos aspectos socioculturais quanto à qualidade da educação, principalmente no que se refere à formação dos professores da referida etapa da educação básica, além de recursos técnicos e financiamento. A partir dessa constatação, ações são idealizadas pelo poder público na forma de programas educacionais e políticas públicas visando a proporcionar melhorias para a educação, geralmente partindo de um projeto de governo e podendo se transformar em uma política de Estado. Esse processo tende a se desenrolar de forma cíclica, isto é, ao passo que os debates sobre o ensino médio no Brasil têm apontado situações contraditórias no âmbito das políticas públicas e das iniciativas direcionadas ao ensino médio, novas 
ações são idealizadas e implementadas, buscando corrigir as lacunas apresentadas anteriormente. Então, novas análises são aplicadas sobre as iniciativas mais atuais, enfatizando fatores inerentes ao seu processo de desenvolvimento e implementação, buscando não apenas identificar falhas, mas também, buscar perspectivas para sua superação.

Estudiosos brasileiros que se debruçam sobre temáticas relacionadas ao ensino médio afirmam que essa etapa da educação básica vem caracterizando uma situação de crise permanente no que diz respeito aos altos índices de reprovação, de evasão e abandono escolar e de distorção idade-série em escala nacional, estadual e local. Associado a isso, ressalta-se a formação inicial deficitária dos professores e a desvalorização dos profissionais, o despreparo dos alunos egressos do ensino fundamental e a precariedade na infraestrutura das escolas. Cabe ressaltar que o despreparo dos docentes, no que se refere à defasagem em sua formação inicial, geralmente é colocado em destaque nos debates como um dos maiores problemas do ensino médio. Frente a tais indicadores, o Ministério da Educação desenvolveu o Programa Ensino Médio Inovador, a partir da Portaria n. 971, de 09 de outubro de 2009, o qual destaca entre seus objetivos o fomento ao desenvolvimento de propostas curriculares inovadoras e projetos pedagógicos que envolvam educação científica e humanística, proporcionando a formação integral, interligando formação geral, ciência e tecnologia, com objetivo de proporcionar a aprendizagem significativa aos estudantes para desenvolvimento de sua autonomia intelectual (BRASIL, 2009, p. 16). Articulado ao Programa Ensino Médio Inovador, o Ministério da Educação instituiu o Pacto Nacional pelo Fortalecimento do Ensino Médio por meio da Portaria $\mathrm{N}^{\circ} 1.140$, de 22 de novembro de 2013. O Programa pode ser considerado como uma das mais atuais iniciativas públicas idealizadas para o desenvolvimento do ensino médio. Trata-se de uma estratégia que, na perspectiva do desenvolvimento de práticas educativas efetivas para o oferecimento de uma educação em nível médio de qualidade, com foco na formação humana integral dos alunos, a partir do oferecimento de cursos de aperfeiçoamento ou de extensão e da disponibilização de apoio técnico e financeiro prestado pelo Ministério da Educação aos professores participantes, visa a

contribuir para o aperfeiçoamento da formação dos professores e coordenadores pedagógicos do ensino médio; promover a valorização pela formação dos professores e coordenadores pedagógicos 
do ensino médio; e rediscutir e atualizar as práticas docentes em conformidade com as Diretrizes Curriculares Nacionais do Ensino Médio - DCNEM (BRASIL, 2013).

A relevância para cultivar o acompanhamento e a análise sistemática das políticas públicas educacionais é defendida por autores como Gatti (2011a), Duarte (2004) e Saviani (2009) a partir de dois fatores principais: o ensino médio, assim como a educação básica num contexto mais amplo, clama por transformações positivas na qualidade da educação, nas condições de trabalho e na superação dos demais problemas vivenciados pela referida etapa; quaisquer iniciativas governamentais para educação, sejam elas na forma de ações estruturantes, programas de incentivo ou de formação continuada, significam investimento de recursos financeiros públicos, portanto, há a preocupação com sua validade e eficácia.

No caso de uma política pública de formação continuada, os processos de avaliação, além dos fatores mencionados, podem envolver a progressão, o posicionamento e a opinião dos participantes sobre o processo de planejamento e implementação de uma determinada ação de formação continuada. Neste sentido, o presente artigo traz no seu âmago a análise do processo de desenvolvimento e implementação do Pacto Nacional pelo Fortalecimento do Ensino Médio na Rede Estadual de Ensino no Município de Aquidauana - MS, buscando relacionar alguns fatores ligados ao cotidiano docente com a formação continuada oferecida pelo Programa, a partir do relato de professores de geografia participantes do Pacto na referida rede de ensino. A análise compõe os objetivos de uma pesquisa educacional associada ao Curso de Mestrado em Geografia do Programa de Pós-graduação da Universidade Federal de Mato Grosso do Sul/CPAQ, estudo financiado pela Fundação de Apoio ao Desenvolvimento do Ensino, Ciência e Tecnologia do Estado de Mato Grosso do Sul (FUNDECT).

Os procedimentos metodológicos envolveram o levantamento do referencial teórico, observação e coparticipação voluntária no processo de implementação do Pacto na Rede Estadual de Ensino de Aquidauana, pesquisa documental com base em índices de rendimento escolar, bem como na legislação inerente ao ensino médio e à formação continuada de professores, aplicação de questionários junto a seis professores de geografia da Rede Estadual de Ensino do município supracitado, que participaram como bolsistas do Programa, e análise de dados. 
Somado à pesquisa bibliográfica sobre o cotidiano docente, o questionário composto por doze perguntas, sendo cinco perguntas dicotômicas mistas e sete abertas, teve o intuito de obter informações referentes aos profissionais no que diz respeito ao tempo de exercício da docência, sua titulação, carga horária, assim como seu posicionamento sobre o suporte técnico e financeiro oferecido pelo Programa e as metodologias adotadas no curso de capacitação, além de informações sobre seu cotidiano docente.

Do quantitativo de oito professores de geografia que participam do referido Programa, apenas seis foram entrevistados. Para a análise dos dados, adotou-se a metodologia qualitativa, considerando que existe uma relação dinâmica nas subjetividades do fator analisado, não se fixando apenas em dados estatísticos, e analisando os dados indutivamente (Kauark; Manhães; Medeiros, 2010, p. 26). Toda pesquisa necessita de um caminho ou direção a ser seguido, visando a sistematizar uma dada problemática, que por sua vez, é conhecido como o método de análise. Segundo Alves (2008, p. 229), o método "é um instrumento organizado que procura atingir resultados estando diretamente ligado à teoria que o fundamenta”. Neste sentido, este trabalho seguiu como caminho o método dialético. De acordo com Alves (2008, p. 235), por meio do método dialético contradizemos (antítese) uma situação inicial (tese), chegando a uma verdade resultante desse conflito (síntese), e também consideramos o comportamento social como resultante de um processo sistêmico.

Com este estudo espera-se contribuir com os debates que envolvem a formação do professor de geografia, no contexto das políticas públicas educacionais direcionadas ao ensino médio, mas acima de tudo, refletindo sobre o desenvolvimento da educação básica de qualidade e a responsabilidade do professor de geografia na produção do conhecimento geográfico em ambiente escolar, na perspectiva de estabelecer novos olhares, novas ações.

\section{Paradigmas dos embates teóricos sobre o ensino médio}

De acordo com os Parâmetros Curriculares Nacionais para o Ensino Médio (BRASIL, 2000, p. 6), no Brasil, essa foi a etapa da educação básica que mais se expandiu a partir da década de 1980. Segundo Neubauer (2011, p. 12), o ensino médio somente recebe atenção expressiva no início do século XXI devido à universalização tardia do ensino fundamental. Porém, 
conforme afirma Castro (2008, p. 114), o ensino médio brasileiro apresenta fatores problemáticos como o despreparo dos alunos egressos do ensino fundamental, a exacerbada flexibilidade nos currículos e o despreparo de professores, que o colocam em uma situação de crise permanente. Esses problemas tendem a compor os debates sobre a educação básica de forma geral, sejam eles realizados tanto em ambiente acadêmico, científico, quanto no campo político. A partir de então, ao longo do processo histórico do ensino médio, políticas públicas foram pensadas no intuito de promover o desenvolvimento e a consolidação dessa etapa da educação básica.

Segundo Simões (2011, p. 112), o conceito de política pública envolve a intervenção estatal, sendo "sempre o resultado de uma interação muito complexa entre o Estado e sociedade”. Para Hofling (2001, p. 31), política pública é uma ação implantada pelo Estado, a partir de "um projeto de governo, através de programas, de ações voltadas para setores específicos da sociedade”. Weber (2003) afirma que é importante compreender a distinção entre política de Estado e política de governo. Segundo o autor,

projetos educacionais que representam propostas em relação às quais foi possível construir amplo consenso social, independente do grupo que ocupasse o poder, como por exemplo, a universalidade do acesso à educação escolar [...], configuram projetos de Estado [...] e projetos que, por dizerem respeito a propostas forjadas em determinada conjuntura política, sinalizam interesses sociais e políticos escolhidos pela sociedade para gerir a coisa pública, em uma instância de poder, pelo período de um mandato [...] projetos de Governo (Weber, 2003, p. 110).

Caracterizando-se como política de Estado ou de governo, tais ações têm despertado uma necessidade de acompanhar seu processo "seja por meio de análise dos desdobramentos da legislação pertinente à sua estrutura, ao seu funcionamento e à sua organização curricular, seja através da interpretação de dados estatísticos” (Zibas; Franco, 1999, p. 9).

No tocante aos programas de formação continuada, o objetivo passa a estar na promoção de mudanças em cognições e práticas, podendo ocorrer tanto por meio de cursos de pós-graduação ou de cursos de curta duração para capacitação de professores, provenientes de sistemas públicos (municipal, estadual e federal) e privados, sendo assim, tanto de forma estruturada, formalizada e institucionalizada, quanto de forma não estruturada, a partir dos mais variados processos em que ocorram 
mudanças cognitivas e de práticas (Gatti, 2011b). De acordo com a literatura, as propostas de formação continuada de professores da educação básica partem de uma problemática principal: a defasagem na formação inicial desses profissionais. Para Rodríguez (2003),

[...] quando analisamos o caráter das políticas de formação de professores, deparamo-nos com uma proposta de "aligeiramento" dessa formação, o que denota uma certa hipocrisia no discurso oficial. Neste sentido, as políticas de formação de professores no Brasil, implantadas durante a década de 1990, são parte de uma política pública que visa [a] adequar o sistema educativo aos requerimentos do processo de reestruturação produtiva, conforme os cânones do neoliberalismo (Rodríguez, 2003, p. 36).

Compreende-se que, ao reduzir a carga horária dos cursos de licenciatura, as abordagens teóricas e práticas se tornam superficiais, o que, somado ao problema da dicotomia entre conhecimento científico e saber pedagógico, torna-se um agravante à política educacional. Portanto, atribui-se um caráter compensatório à formação continuada, tendo em vista que seu viés comumente tem sido associado à necessidade de suprir determinada "precariedade na formação inicial" e não à busca por atualização/qualificação profissional (Gatti, 2011b, p. 186-187).

Uma ação de formação continuada deve dar condições para que o professor possa "compartilhar com os colegas trocas de experiências e qualificação continuada para que o processo de ensino e aprendizagem adquira novos significados, não só para o aluno como também para o professor" (Osório, 2003, p. 218). Em um programa de formação continuada, a formação do professor "não pode ser dissociada do problema das condições de trabalho que envolve a carreira docente, em cujo âmbito deve ser equacionado às questões do salário e da jornada de trabalho" (Saviani, 2009, p. 153).

A formação continuada de professores, então, expressa uma reflexão sobre o cotidiano docente, abarcando não apenas a análise sobre suas práticas pedagógicas, seu papel na formação do indivíduo e na construção do conhecimento, seus princípios e valores, mas também sobre suas condições de trabalho e problemas que fazem parte da realidade escolar e da educação como um todo.

Segundo Zibas (2005, p. 1068), a educação é um "campo de luta cujas contradições podem tanto reforçar a estratificação social quanto 
contribuir para a democratização”. Para Pontuschka (2013, p. 436), tais contradições estão associadas à "quantidade e qualidade da educação, entre função e objetivos". Tendo em vista que essas iniciativas significam investimento de recursos públicos, surgem, principalmente a partir da multiplicação de propostas de formação continuada, questionamentos sobre o alcance dos objetivos ou sobre os respectivos resultados, gerando "preocupações quanto à criteriosidade, validade e eficácia desses cursos" (Gatti, 2011, p. 190).

Tais questionamentos incentivam pesquisas educacionais que, por sua vez, vêm apontando a presença de problemas em programas de formação continuada de professores, principalmente no que se refere a aspectos infraestruturais e técnicos. Neste sentido, torna-se de suma importância o acompanhamento contínuo das iniciativas públicas, principalmente na perspectiva de diagnosticar problemas que, por sua vez, poderão ser superados, caracterizando-se assim como um processo cíclico.

Narrativas dos professores de geografia sobre o cotidiano docente no município de Aquidauana - MS

Problematiza-se aqui o cotidiano docente na Rede Estadual de Ensino no Município de Aquidauana - MS, enfatizando questões referentes aos obstáculos enfrentados pelos professores de geografia no exercício de sua profissão.

Um dos principais problemas encontrados é a dificuldade para conciliar trabalho, família e lazer. De forma geral, os professores estão submetidos a uma rotina desgastante devido ao frenético calendário escolar, reduzido tempo dedicado à preparação de aulas e elevada carga horária. Outra barreira no cotidiano docente é a insuficiência dos recursos técnicos e financeiros apresentados pelas escolas, uma vez que não atendem à demanda dos professores. Desta forma, utilizando os recursos disponibilizados pela escola, as metodologias adotadas limitam-se a atividades com mapas, uso da sala de tecnologia para pesquisa bibliográfica, aulas expositivas e dialogadas com emprego de projetores, livro didático, quadro de giz, além da utilização de jornais e revistas adquiridas com recursos financeiros pessoais, e raramente conseguindo realizar aula extraclasse. 
Quando questionados sobre as dificuldades encontradas no planejamento das aulas, os professores entrevistados destacaram os seguintes fatores: curta duração das aulas; insuficiência nos recursos tecnológicos, financeiros e humanos; falta de tempo para planejamento; a distribuição das aulas ao longo do calendário escolar, além da apatia dos alunos. Os professores afirmaram ter dificuldades para adotar metodologias práticas para trabalhar com temas relacionados à questão ambiental, bem como para contextualizar os conteúdos que compõem o referencial curricular. Segundo eles, as escolas também não dispõem de laboratórios de geografia e estrutura física que ofereçam condições de trabalho para que possa fluir melhor o pensar e o fazer pedagógico.

Como possibilidades para mitigação de problemáticas aqui sistematizadas no presente estudo, os professores enumeraram iniciativas como: estabelecimento de parcerias junto às universidades que oferecem cursos de licenciatura, especificamente em geografia, para desenvolvimento de materiais didáticos e paradidáticos, bem como metodologias de ensino mais dinâmicas, porém contextualizadas à realidade escolar, passando a escola a contar com a participação em conjunto entre professores da educação básica, professores da educação superior e alunos de graduação.

Tendo em vista os anseios evocados pelo cotidiano docente na realidade local, considerou-se relevante averiguar também as iniciativas públicas direcionadas ao desenvolvimento da educação básica e à valorização do profissional da educação. Desta forma, a seguir apresenta-se uma análise do programa Pacto Nacional pelo Fortalecimento do Ensino Médio, enfatizando os professores de geografia da Rede Estadual de Ensino de Aquidauana - MS, tal como sua abordagem metodológica sobre o ensino do referido componente curricular.

\section{A implantação e implementação do Pacto Nacional Pelo Fortalecimentodo Ensino Médiona Rede Estadual de Ensino de Aquidauana - MS}

O Pacto Nacional pelo Fortalecimento do Ensino Médio é uma das mais atuais iniciativas do Governo Federal, tendo como foco a valorização dos profissionais de educação a partir do oferecimento da formação continuada. Instituído pela Portaria $\mathrm{N}^{0} 1.140$, de 22 de novembro de 2013 do MEC, o Programa apresenta como objetivo o aperfeiçoamento da 
formação dos professores e coordenadores pedagógicos do ensino médio, promovendo a valorização desses profissionais (BRASIL, 2013), a partir do oferecimento de apoio técnico, na forma de curso de formação continuada, e financeiro (bolsa de estudos). O processo formativo dos professores foi organizado em duas etapas. A primeira etapa dedica-se à discussão sobre temas relacionados ao ensino médio de forma geral, tendo como base as Diretrizes Curriculares Nacionais para o Ensino Médio. A segunda etapa abre espaço para "a reflexão a respeito das áreas de conhecimento e das relações entre elas e seus componentes curriculares” (BRASIL, 2013, p. 6).

No município de Aquidauana - MS, a primeira etapa se deu no período de março a dezembro de 2014. Mensalmente, eram reservados dois dias para a realização dos encontros, geralmente nas sextas-feiras, nos períodos matutino, vespertino e noturno, e aos sábados no período matutino. Constatou-se a opção pela adoção do esquema de ação-reflexãoação. Participou do curso de formação continuada o quantitativo de 118 professores que atuam na Rede Estadual de Ensino nos espaços urbano, rural e em comunidades indígenas. Os encontros aconteceram na Escola Estadual Coronel José Alves Ribeiro (CEJAR), localizada na área central da cidade, facilitando a mobilização espacial de todos os participantes. Desse quantitativo, oito são professores de geografia. A coordenação da formação foi composta por 10 coordenadoras pedagógicas de diferentes escolas, que ministraram as oficinas do curso de capacitação, sendo as responsáveis pela orientação dos estudos, assim como pelo monitoramento e controle da frequência dos professores cursistas.

A metodologia adotada para trabalhar os temas propostos pelo Programa se deu em forma de dinâmicas de grupo, desenvolvendo atividades como teatro, produção de vídeo, painéis com colagens, jornal falado, paródia, poemas e jogos. Também foram realizadas palestras, leitura e diálogos. Como referencial teórico, foram adotados os cadernos disponibilizados no portal on-line do Programa, apresentando as seguintes temáticas: Ensino Médio e Formação Humana Integral; O Jovem como Sujeito do Ensino Médio; Currículo do Ensino Médio; Áreas de Conhecimento e Integração Curricular; Organização e Gestão do Trabalho Pedagógico; Avaliação no Ensino Médio.

Devido à falta de espaço no calendário escolar, em razão das demais atividades desenvolvidas pelas escolas, o espaço para discussão sobre os temas propostos para a segunda etapa se limitou apenas a um encontro, 
com duração de quatro horas, realizado no dia 28 de março de 2015. Nesse encontro foram trabalhados, de forma peculiar, os temas: Organização do Trabalho Pedagógico no Ensino Médio; Ciências Humanas; Ciências da Natureza, Linguagens, Matemática.

As atividades foram organizadas da seguinte forma: formação de grupos - direcionamento dos professores dependendo da relação entre o componente curricular que atua com as grandes áreas do conhecimento; estabelecimento de debates nos quais os temas eram trabalhados isoladamente dos demais grupos, a fim de discutir quais contribuições as grandes áreas do conhecimento podem direcionar para a formação integral do aluno, integrando cultura, trabalho, ciência e tecnologia; e apresentação das considerações finais junto aos demais grupos.

Atualmente o programa foi desativado pelo MEC, conforme contato estabelecido por e-mail junto ao Portal do Pacto Nacional pelo Fortalecimento do Ensino Médio: "informamos que o programa Pacto Nacional pelo Fortalecimento do Ensino Médio foi desativado pelo Ministério da Educação" (MEC/SEB, 2015).

Relato dos professores de geografia da Rede Estadual de Ensino de Aquidauana MS sobre o Pacto Nacional pelo Fortalecimento do Ensino Médio

Por meio de entrevistas realizadas durante o mês maio de 2015, foram coletadas narrativas com exposição do ideário docente sobre o Pacto. Dos oito professores de geografia da Rede Estadual de Ensino de Aquidauana, que participaram do curso de formação oferecido pelo Pacto, apenas seis aceitaram participar da pesquisa.

Com relação à jornada de trabalho, os docentes ressaltaram que sua carga horária está submetida a uma rotina maçante, com lotação semanal variando entre 12, 20, 30, 40 e 60 horas. Outro ponto ressaltado pelos professores refere-se à necessidade de completar a carga horária em mais de uma escola. Há registro de casos em que, no anseio por condições econômicas para manter o orçamento familiar, o professor necessita assumir encargos docentes excessivos, distribuídos em duas ou mais escolas.

O aperfeiçoamento profissional, a busca por novas informações e conhecimentos, a troca de experiências relacionadas à utilização de metodologias de ensino, além da necessidade de se entender o discente no contexto atual, foram os motivos enumerados pelos entrevistados, que 
os levaram a ingressar no Pacto. Um dos entrevistados afirmou que sua participação no Programa se deu pela exigência da direção escolar e da coordenação pedagógica da escola na qual trabalha. Consideram-se, nesta situação, duas possibilidades: no caso, o professor não apresenta interesse em buscar o enriquecimento curricular, iniciativa que faz parte do processo de busca por novas perspectivas para fluir melhor sua profissão; tal motivo para a participação em uma ação de formação continuada pode leva-lo a manter uma postura passiva durante o desenvolvimento das atividades propostas, o que, possivelmente, pouco contribuirá para mudanças em suas cognições e práticas.

Quanto ao suporte financeiro, três dos professores entrevistados não estão satisfeitos, justificando que a ajuda de custo oferecida não compensa a sobrecarga do docente, portanto, a bolsa mensal de $\mathrm{R} \$ 200,00$, que foi paga em 12 meses, não se configurou como fator de incentivo. Por outro lado, os outros entrevistados afirmaram estar satisfeitos, enxergando o suporte financeiro oferecido pelo Pacto como uma ajuda adicional e que sua principal motivação está na ampliação de conhecimentos.

Em relação aos recursos tecnológicos e procedimentos pedagógicos (suporte técnico), a inoperância de equipamentos como os tablets distribuídos pelo programa, assim como a baixa diversificação dos recursos tecnológicos e a falta de espaço para abordagem sobre metodologias de ensino de geografia, acarretaram insatisfação de alguns dos entrevistados. Eles ressaltaram que há dificuldade para colocar em prática as metodologias apresentadas durante o curso de capacitação, principalmente quanto às práticas com abordagens interdisciplinares. Outros problemas foram relacionados à duração dos encontros, à falta de espaço no calendário letivo para realização e à falta de transporte para aqueles que residem distante do local designado para a formação, como em zona rural.

Inquiridos sobre as opiniões e sobre as metodologias adotadas durante a etapa de formação comum (primeira etapa), realizada em conjunto com professores de todas as áreas, os entrevistados enumeraram como pontos positivos a interação e a reflexão coletiva, ressaltando como pontos negativos: "os encontros se tornaram exaustivos devido ao seu tempo de duração"; "Houve pouco espaço para discussão a respeito de problemas vivenciados no ensino médio"; "As atividades se mostraram repetitivas". Os professores consultados consideram que não houve tempo 
para tratar sobre metodologias de ensino específicas para conteúdos do componente curricular de geografia.

A abordagem temática adotada na segunda etapa foi entendida pelos entrevistados como um problema, por desconsiderar as especificidades de cada componente curricular, da mesma forma que não contemplou as dificuldades que o professor de geografia enfrenta em suas práticas pedagógicas. Segundo os professores, o Programa poderia ter aplicado oficinas com utilização de tecnologias da informação e comunicação no processo de ensino e aprendizagem, especificamente com aplicação das geotecnologias; poderia ter aberto maior espaço para temas transversais e discussão sobre formas mais efetivas para promover a articulação entre as escolas, os professores e o poder público; poderia ainda enfatizar a abordagem sobre metodologias de ensino para trabalhar conteúdos previstos no referencial curricular de geografia e também ampliar o número de profissionais qualificados para aplicar atividades específicas voltadas ao ensino e aprendizagem das disciplinas.

Os docentes ressaltaram que a abordagem apresentada pelo Pacto não foi suficiente para resolver todos os problemas vivenciados pelo ensino médio, porém abre espaço para debates pertinentes, enfatizando que tais problemáticas são complexas, ultrapassando os limites da escola, envolvendo questões socioculturais e políticas, estas últimas englobando as escalas municipal, estadual e nacional. Em relação à opinião dos docentes sobre o processo de planejamento das ações do Pacto, de forma geral, sentem que a realidade escolar, o cotidiano docente, especificamente as suas dificuldades ligadas ao exercício da profissão, são fatores levados em consideração nesse processo de planejamento, pois segundo eles, nos encontros, foram discutidas algumas questões que compõem a realidade escolar, porém com pouco aprofundamento. Por outro lado, há consenso entre eles na ideia de que, ao analisar as abordagens temáticas e metodológicas aplicadas na formação oferecida pelo Programa, o seu processo de planejamento não considerou as diferentes realidades apresentadas em cada escola, localidade, região.

\section{Considerações finais}

Ao analisar o cotidiano docente na Rede Estadual de Ensino no Município de Aquidauana - MS e o processo de implantação e 
implementação do Pacto Nacional pelo Fortalecimento do Ensino Médio no referido município, foi possível enumerar algumas situações conflitantes no que diz respeito à capacitação e valorização no contexto da política pública educacional brasileira. As contradições presentes nas políticas públicas de formação continuada permitem a definição de um ideário de que o planejamento das ações não são reflexos da compreensão da realidade escolar.

Mesmo considerando que os professores são conscientes da importância de se manter em constante qualificação, sendo as ações de formação continuada um elemento essencial para a atualização de conhecimentos e para o aperfeiçoamento profissional, além de inserir o profissional de educação nos debates temáticos relacionados ao ensino médio, possibilitando encontrar medidas mitigadoras, a incoerência no processo de planejamento, implantação e implementação em relação às reais necessidades inerentes ao cotidiano docente e à realidade escolar pode gerar insatisfação quanto às políticas públicas de formação continuada, podendo prejudicar a progressão dos cursistas. Neste caso, é possível considerar a ineficácia do investimento do poder público sobre a formação do professor, partindo da possibilidade de que uma grande parcela desses profissionais venha a manter um posicionamento alienado, não participativo nas atividades propostas, não implicando mudanças em suas cognições e práticas pedagógicas.

Promover a interdisciplinaridade é uma das ações incentivadas (teoricamente) pelas políticas públicas educacionais, especificamente pelo Pacto Nacional pelo Fortalecimento do Ensino Médio. Porém, a atenção que se dá nas escolas para o cumprimento do calendário escolar, a forma em que são distribuídas as aulas e a hora atividade, além da necessidade que os docentes têm de lotar suas cargas horárias, em duas ou mais escolas, torna impossível a reunião entre os docentes para planejamento de atividades com tal abordagem.

Os profissionais encontram dificuldades para desenvolver atividades práticas e diversificar suas metodologias, problema também intrínseco à formação inicial. Somado a isso, as escolas não dispõem de recursos técnicos e financeiros suficientes para aplicação de atividades mais dinâmicas, o que, associado ao espaço físico inadequado, ausência de laboratórios de geografia, impede a aquisição e utilização de equipamentos tecnológicos, bem como a realização de atividades práticas, além da questão burocrática que acaba impedindo a realização de aulas de campo. 
Assim, quanto à abordagem metodológica para trabalhar com conteúdos da geografia escolar, com foco na contextualização e significação do saber geográfico para os alunos, elencada pelos professores como um dos principais motivos que os levaram a participar do Pacto, despertou um sentimento de frustração, uma vez que, tal abordagem não foi em nenhum momento contemplada.

Relacionando o tempo de exercício da docência com o número de professores que possuem pós-graduação, eles se sentem embargados para ingressar nessa etapa de aperfeiçoamento. Tal desmotivação se associa às próprias condições de trabalho já mencionadas, somando-se a falta de uma política pública que possibilite a inserção desses profissionais em cursos de pós-graduação strictu sensu isentos de custos pessoais, não interferindo no plano de carreira ou prejudicando sua remuneração, sua relação familiar e, consequentemente, sua qualidade de vida.

O Pacto Nacional pelo Fortalecimento do Ensino Médio na Rede Estadual de Ensino de Aquidauana também apresentou, segundo os entrevistados, problemas associados à inoperância de equipamentos tecnológicos e à inserção da metodologia adotada nos encontros em suas práticas docentes. Os professores manifestaram-se insatisfeitos com a duração exaustiva dos encontros, além de afirmarem que as atividades se apresentaram repetitivas, levando-os a, gradativamente, abandonar um posicionamento inicialmente crítico e participativo, para um passivo durante a realização dos encontros.

A insatisfação também foi devida à superficialidade atribuída ao tratamento dos temas propostos e ao esgueirar de temas em que os docentes mais ensejavam: metodologias de ensino para a geografia escolar, utilização de geotecnologias, e abordagem prática de temas. Considera-se que, durante a etapa de formação específica, a organização dos temas e dos grupos para debate, de acordo com as grandes áreas do conhecimento, desassistiu as especificidades dos componentes curriculares.

Neste sentido, no tocante ao processo de ensino e de aprendizagem da geografia escolar, o Pacto se configurou inoperante na perspectiva da promoção de mudanças de práticas e atitudes, uma vez que a desativação do Programa foi confirmada pelo Ministério da Educação.

Os entrevistados sugeriram que no decorrer dos encontros de formação continuada houvesse espaço para discutir caminhos que promovam a articulação entre as escolas e instituições de ensino superior 
no viés da aproximação entre os cursos de licenciaturas e a educação básica, para que professores do ensino médio, professores da educação superior e alunos de licenciatura possam interagir, estabelecer parcerias, desenvolver recursos didáticos e metodológicos a serem aplicados nas escolas, especificamente na geografia escolar. Quanto à opinião geral sobre o Pacto, considera-se que o tempo foi escasso para discutir os problemas enfrentados pelo ensino médio, assim como no ensino da geografia. Como os professores sentiram que os principais problemas enfrentados em seu cotidiano não foram comtemplados de forma aprofundada e consistente, há consenso de que não houve estudo sobre tais questões no processo de planejamento do Programa, assim como as diferentes realidades escolares e docentes não foram consultadas. Dessa maneira, é possível inferir que as ações do Pacto surtirão pouco efeito sobre os procedimentos metodológicos dos docentes envolvidos, assim como sobre o ensino médio de forma geral.

Analisando as respostas dos professores de geografia entrevistados, somando-se as informações obtidas com observações e discussões realizadas durante as duas etapas do Programa, bem como com o relato dos professores de geografia da Rede Estadual de Ensino de Aquidauana sobre o cotidiano docente, é possível considerar que o Pacto Nacional pelo Fortalecimento do Ensino Médio na Rede Estadual de Ensino no Município de Aquidauana - MS se caracterizou como um espaço através do qual os profissionais de educação envolvidos com o ensino médio, e com a geografia escolar, puderam expor e discutir sobre os principais problemas vivenciados em seu cotidiano profissional, possibilitando elencar ações mitigadoras para grande parte desses problemas, porém, a superficialidade na qual foram tratados os temas se apresenta como um problema a ser superado nas futuras políticas públicas.

\section{Referências}

ALVES, F. D. Considerações sobre métodos e técnicas em geografia humana. DIALOGUS, Ribeirão Preto, SP, v. 4, n. 1, p. 227-241, 2008.

BRASIL. Ministério da Educação. Secretaria de Educação Básica. Ensino médio inovador. Brasília: Ministério da Educação, 2009.

. Secretaria de Educação Básica. Pacto Nacional pelo Fortalecimento da Ensino Médio: Formação de Professores do Ensino Médio - Documento Orientador Preliminar. Brasília: Ministério da Educação, 2013. 
Portaria $N^{o}$ 1.140, de 22 de Novembro de 2013. Institui o Pacto Nacional pelo Fortalecimento do Ensino Médio e define suas diretrizes gerais, forma, condições e critérios para a concessão de bolsas de estudo e pesquisa no âmbito do ensino médio público, nas redes estaduais e distrital de educação, 2013.

_. Parâmetros Curriculares Nacionais para o Ensino Médio. Disponível $\overline{\mathrm{em}} \mathrm{<}$ <ttp://portal.mec.gov.br/seb/arquivos/pdf/blegais.pdf $>$. Acesso em: 20 nov. 2015.

. Secretaria de Educação Básica. Publicação eletrônica [mensagem pessoal]. Mensagem recebida por < raphaeldeleao@hotmail.com>, em 28 dez. 2015.

CASTRO, C. M. O Ensino Médio: órfão de ideias, herdeiro de equívocos. Ensaio: avaliação de políticas públicas educacionais. Rio de Janeiro, v. 16, n. 58, p. 113124, jan./mar. 2008.

DUARTE, V. C. Capacitação docente em Minas Gerais e São Paulo: uma análise comparativa. Cadernos de Pesquisa, São Paulo, v. 34, n. 121, p. 139-168, jan./abr. 2004.

GATTI, B. A. Análise das políticas públicas para formação continuada no Brasil, na última década. In: GARCIA, W. E. (Org.). Perfis da educação: textos selecionados de Bernadete A. Gatti. Belo Horizonte: Autêntica, 2011a. p. 185-203.

. A formação dos docentes: o confronto necessário professor x academia. In: GARCIA, W. E. (Org.). Perfis da educação: textos selecionados de Bernadete A. Gatti. Belo Horizonte: Autêntica, 2011b. p. 151-159.

HOFLING, E. M. Estado e políticas (públicas) socais. Cadernos Cedes, ano 21, n. 55, p. 30-41, nov. 2001.

KAUARK, J.; MANHÃES, C. F.; MEDEIROS, C. H. Metodologia da pesquisa: guia prático. Itabuna: Via Litterarum, 2010.

NEUBAUER, R. et al. Ensino médio no Brasil: uma análise de melhores práticas e de políticas públicas. Revista Brasileira de Estudos Pedagógicos, Brasília, v. 92, n. 230, p. 11-33, jan. 2011.

OSÓRIO, A. M. N. Formação inicial e continuada dos professores: implicações em sua prática pedagógica. In: . (Org.). Trabalho docente: os professores e sua formação. Campo Grande, MS: UFMS, 2003. p. 217-238.

PONTUSCHKA, N. N. Políticas públicas na trajetória do ensino e da formação dos professores: a construção do conhecimento. In: ALBUQUERQUE, M. A. M. de; FERREIRA, J. A. S (Org.). Formação, pesquisa e práticas docentes: reformas curriculares em questão. João Pessoa: Mídia, 2013. p. 433-435.

RODRÍGUEZ, M. V. Formação de professores: uma política de qualificação ou desqualificação do trabalho docente? In: OSÓRIO, A. M. N. (Org.). Trabalho docente: os professores e sua formação. Campo Grande, MS: UFMS, 2003. p. 35-54. 
SAVIANI, D. Formação de professores: aspectos históricos e teóricos do problema no contexto brasileiro. Revista Brasileira de Educação, v. 14, n. 40, p. 143-155, jan./abr. 2009.

SIMÔES, C. A. Políticas públicas do ensino médio: iniciativas governamentais e o Ensino Médio Inovador. Revista Retratos da escola, Brasília, v. 5, n. 8, p. 111125, jan./jun. 2011.

WEBER, S. Políticas educacionais, práticas escolares e objetivos de aprendizagem: repercussões na sala de aula. In: LISITA, V. M. S. S.; SOUZA, L. F. E. C. P. (Org.). Políticas educacionais, práticas escolares e alternativas de inclusão escolar. Rio de Janeiro: DP\&A, 2003. p. 11-24.

ZIBAS, D. M. L.; FRANCO, M. L. P. B. O Ensino Médio no Brasil neste final do século: uma análise de indicadores. São Paulo: FCC/ DPE, 1999. (Textos FCC, nº 18).

ZIBAS, D. M. L. Reformular o ensino médio? Alguns antecedentes e atuais desdobramentos das políticas dos anos de 1990. Educação e Sociedade, Campinas, v. 26, n. 92, p. 1067-1086, out. 2005.

Raphael de Leão Duarte - Possui graduação em Geografia pela Universidade Federal de Mato Grosso do Sul, Mestrado em Geografia pela Universidade Federal de Mato Grosso do Sul. Atualmente é professor da Rede Municipal de Educação de Campo Grande - MS.

Vicentina Socorro da Anunciação - Possui graduação em Geografia Licenciatura Plena e Bacharelado pela Universidade Federal de Mato Grosso do Sul (1996), mestrado em Geografia pela Universidade Estadual Paulista Júlio de Mesquita Filho (2001) e doutorado em Geografia pela Universidade Estadual Paulista Júlio de Mesquita Filho (2009). Atualmente é professora adjunta da Universidade Federal de Mato Grosso do Sul. Tem experiência na área de ensino da geografia, Geociências, com ênfase em Climatologia Geográfica, Geografia da Saúde e desastres naturais; atuando principalmente nos seguintes temas: urbano, clima, ambiente, saúde, hazards climáticos e ensino.

Contribuição dos autores no desenvolvimento do trabalho

O estudo foi concebido e estruturado por ambos os autores. O primeiro autor ficou responsável pela coleta, análise de dados, desenvolvimento teórico-conceitual e redação do texto. O segundo autor ficou responsável pela revisão da escrita e contribuições teóricoconceituais, bem como pela tradução do texto.

Recebido para publicação em 3 de janeiro de 2017. Aceito para publicação em 10 de fevereiro de 2017. 